\title{
EL DESAFÍO DE UNA EDUCACIÓN NO SEXISTA EN LA FORMACIÓN INICIAL: PRÁCTICAS DOCENTES DE EDUCADORAS DE PÁRVULO EN ESCUELAS PÚBLICAS CHILENAS ${ }^{1,2}$
}

\author{
Ximena Azúa ${ }^{3}$, \\ Daniela Lillo ${ }^{4}$, \\ Pamela Saavedra ${ }^{5}$
}

\section{RESUMEN}

El sexismo en la educación se posicionó en 2018 como el principal tema de los movimientos estudiantiles. Este sexismo se identifica en todos los niveles educativos; entre ellos la educación parvularia, momento relevante en la vida de los niños, ya que es durante la primera infancia donde ocurre la socialización primaria y se internalizan significaciones del mundo social. A partir de esto, surge la interrogante respecto de la práctica docente en este nivel y de los posibles sesgos de género allí presentes. El siguiente artículo analiza las tipologías sobre sesgos y estereotipos de género en la práctica docente de las educadoras de párvulo. El estudio contempla el análisis descriptivo, de las dimensiones y subdimensiones, obtenido tras la aplicación de pautas para guiar la revisión de videos de evaluación docente. Los resultados permiten concluir que existe una prominente naturalización de prácticas sexistas de forma transversal en todos los tramos y edades por parte de las educadoras, lo que genera una necesidad urgente de incorporar con mayor énfasis y prioridad la formación docente con enfoque de género en educación parvularia.

Conceptos clave: educadoras de párvulos, política de educación, prácticas docentes, rol de educación, sexismo.

\section{THE CHALLENGE OF NON-SEXIST EDUCATION IN INITIAL TEACHER TRAINING: PRESCHOOL TEACHERS' PRACTICES IN CHILEAN PUBLIC SCHOOLS}

\section{ABSTRACT}

The issue of sexism in education moved to the forefront of the student movements, in 2018. While it has been identified at every educational level, its presence in early childhood education is of particular concern, since that is where early socialization occurs, and meanings of the social world

El uso del génerico masculino utilizado en este artículo responde a las normas editoriales de la revista Calidad en la Educación y no representa la posición de las autoras respecto al uso de lenguaje inclusivo.

2 Este estudio contó con el apoyo financiero del PNUD, proyecto Nº 031/2017.

Universidad de Chile, Santiago, Chile. Contacto: xazua@uchile.cl

4 Universidad de Chile, Santiago, Chile. Contacto: danie.lillo.m@gmail.com

5 Universidad de Chile, Santiago, Chile. Contacto: pamela.saavedra.c@gmail.com 
are internalized. Thus, this study explores possible gender biases in teaching practices at this level and analyzes typologies on gender biases and stereotypes in the teaching practice of preschool educators. The study includes a descriptive analysis of the dimensions and subdimensions, according to the information gleamed from the guided viewing questions applied to videos from the annual teacher evaluation. The main results indicate there is significant naturalization of sexist practices by educators of all grades and ages, which generates an urgent need to incorporate, emphasize and prioritize a gender focus in training future preschool educators.

Key concepts: education policy, educational practices, preschool teachers, role of education, sexism.

\section{Introducción}

En 2018 el sexismo en la educación se posicionó como la principal exigencia de los movimientos estudiantiles. Si bien esta interpelación se ha manifestado más patentemente desde los estudiantes universitarios y secundarios, el cuestionamiento por lo que se enseña y cómo se enseña, así como las interacciones que se desarrollan en el espacio educativo apunta a todos los niveles de educación formal escolar y universitaria.

En este contexto, la práctica docente es uno de los aspectos para reflexionar en torno a la educación no sexista: el material y diseño pedagógico seleccionado y utilizado por el profesorado, así como el lenguaje utilizado en aula y los modos de interactuar con los estudiantes afectan la producción y reproducción de relaciones de poder en la escuela, donde uno de los niveles más cruciales es la educación parvularia debido a que, si bien los niños ya traen consigo una socialización de género desde la esfera familiar, se encuentran en una etapa formativa inicial donde se comienza a forjar la normalización de ciertas ideas y conductas.

Una de las formas de conocer las prácticas docentes que se desarrollan en el aula es el Sistema de Evaluación del Desempeño Profesional Docente (o evaluación docente), mecanismo a cargo del Ministerio de Educación de Chile (Mineduc), que consiste en una evaluación obligatoria para los docentes que se desempeñan en aula en los establecimientos municipales y que tiene por objetivo "fortalecer la profesión docente y contribuir a mejorar la calidad de 
la educación" (Portal Docente Más, s/f). Esta evaluación se realiza con cuatro instrumentos, los que se construyen a partir de los dominios y criterios indicados por el Marco para la buena enseñanza $a^{6}$; cada instrumento recopila información de distintos ámbitos: práctica en el aula, visión del docente acerca de su propio desempeño, opinión de sus pares y de sus jefaturas (Portal Docente Más, s/f).

En función de lo anterior, el presente artículo expone los resultados de una investigación mayor en torno a los sesgos de género al interior del aula, hecha mediante la revisión de videos de clases realizados en el marco de la evaluación docente (Facultad de Ciencias Sociales de la Universidad de Chile et al., 2017). Estos resultados están enfocados en el nivel de educación parvularia debido a que, al ubicarse esta como un órgano de socialización primaria junto con la familia, los sesgos de género presentes en las prácticas docentes de este nivel afectan de forma crucial la reproducción de desigualdades que perpetúa una educación sexista.

\section{Breve marco teórico}

\subsection{Género y escuela}

Al ingresar al sistema escolar los niños ya poseen estereotipos de género (Luke, 2000), los cuales son posteriormente reforzados en la escuela, institución que diversos estudios han identificado como uno de los principales focos de la reproducción de desigualdades sociales entre hombres y mujeres, donde las mujeres se posicionan en un lugar de subordinación frente a los hombres (Guerrero, Provoste y Valdés, 2006; Rosetti, 1993; Servicio Nacional de la Mujer, Sernam, 2009; Subirats \& Brullet, 1992), pues como señala Valdés (2013): "el género está presente en todas estas instancias que conforman el sistema educativo, lo producen y reproducen" (p. 56).

Esta socialización de género producida y reproducida en la escuela se lleva a cabo a través de diversos factores, entre ellos los

6 El Marco para la buena enseñanza consiste en una guía de estándares para la enseñanza y la práctica profesional docente, señalando las responsabilidad del saber y hacer del docente en el aula, escuela y comunidad escolar (Ministerio de Educación de Chile y Centro de Perfeccionamiento, Experimentación e Investigaciones Pedagógicas, CPEIP, 2008). 
contenidos que se transmiten -y cómo se transmiten- a través del currículo, los libros de textos y los docentes, así como también por medio de la interacción de los estudiantes entre sí y de estos con el profesorado. Del mismo modo, dicha socialización también se reproduce a través de la manera en que se verbalizan estas interacciones, situando el uso de lenguaje genérico masculino como un aspecto relevante, pues invisibiliza a las mujeres y diversidades sexuales al interior del aula. Respecto del currículo oculto, Rosetti (1993) plantea esta situación como una pedagogía oculta de género y la define como aquella que "vincula creencias, actitudes y concepciones que llevan a ambos sexos a internalizar roles tradicionales" (p. 38). Del mismo modo, en relación con las interacciones del profesorado con los estudiantes, diversos estudios han constatado reiteradamente que los docentes — hombres y mujeres — dedican más atención a los niños que a las niñas, lo que se expresa en la realización de más preguntas y mayores indicaciones, entre otros aspectos (Subirats, 1994).

Un reciente artículo que aborda la realidad de los profesores de ciencias en Chile, pero que puede ser aplicado para todos los niveles educativos, indica:

No se ha incluido la perspectiva de género en el currículo nacional y recientemente se están discutiendo orientaciones para incorporarse en la formación del profesorado de ciencias. Esto hace que la perspectiva de género sea vista desde fuera, porque no se relaciona con los procesos culturales y se reduce solo a la dimensión biológica de sexo binario (Camacho, 2018, p. 113).

En el contexto latinoamericano, se puede observar esta realidad ya en el nivel preescolar. Un ejemplo de ello es el trabajo de Corrales et al. (2005), donde a partir de un estudio exploratorio se analizó la información aportada por los docentes a través de un cuestionario, con la finalidad de conocer las manifestaciones de sexismo desarrolladas dentro de aulas de preescolar en Costa Rica. Una de las conclusiones indicó que para los docentes las conductas sexistas de sus alumnos obedecen a patrones de actuación producto de la influencia de sus hogares, entre las que se cuenta la minimización de la capacidad de la mujer o la maximización de la del hombre en detrimento de la 
potencialidad femenina. Otro ejemplo que puede mencionarse en la misma línea es el estudio de Chávez (2006), donde se constata que los estereotipos de género están presentes en la cotidianidad del aula de diversas maneras. El estudio concluyó, por ejemplo, que algunas de las formas en las que se expresa el sexismo es el lenguaje, el currículo, el material educativo utilizado (cuentos, poesías, rimas, canciones, etc.). Los resultados permiten indicar, en consecuencia, que todas las personas son reproductoras de desigualdades, de allí que sea fundamental promover los procesos de autorreflexión en los docentes, haciéndoles conscientes de ello. Igualmente, resulta fundamental revisar la formación profesional del profesorado, espacio en el cual los estudios de género están ausentes.

Por su parte, el análisis publicado por Finco (2015) respecto de la realidad brasileña da cuenta de las relaciones de género observadas en guarderías y jardines de infancia, reconociendo que la escuela no es neutra, ya que participa sutilmente de la construcción de la identidad de género, y de forma desigual. De este modo, dicha construcción se inicia desde las primeras relaciones de los niños en el ambiente colectivo de la educación infantil, por lo tanto, plantear las relaciones de género en la formación de docentes de educación parvularia significa, entre otros aspectos:

- considerar este espacio como un lugar de confrontación y convivencia con las diferencias;

- pensar en cursos de formación para docentes, considerando que en Chile la mayoría de estos profesionales son mujeres;

- implica reflexionar en torno a las propuestas pedagógicas, atendiendo a las características del trabajo de cuidar y educar a niños pequeños y sus relaciones con las características construidas socioculturalmente por el trabajo femenino y, sobre todo,

- conlleva a debatir los valores adultocéntricos, androcéntricos y homofóbicos de nuestra sociedad.

Los tres estudios revisados, que tienen como foco a los docentes del nivel preescolar, permiten observar coincidencias en sus reflexiones y conclusiones a pesar de los enfoques aplicados y las diferencias actitudinales del profesorado, estableciendo lo esencial 
54 EL DESAFÍO DE UNA EDUCACIÓN NO SEXISTA EN LA FORMACIÓN INICIAL: PRÁCTICAS DOCENTES DE EDUCADORAS DE PÁRVULO EN ESCUELAS PÚBLICAS CHILENAS - X. Azúa, D. Lillo, P. Saavedra

que es para la educación inicial contar con docentes que tomen conciencia de las identidades y subjetividades que se construyen en las interacciones de la sala de clase, de modo de implementar acciones de cambio que promuevan relaciones interpersonales más equitativas y menos marcadas por el sexismo.

Ahora bien, la socialización de género de carácter patriarcal producida y reproducida en la escuela en la que se posiciona lo masculino por sobre lo femenino (Pateman, 1988), se comprende como violencia de género, puesto que:

- se traduce en una desigualdad en los aprendizajes, lo que se observa en la diferencia de resultados de hombres y mujeres en pruebas internacionales (Castillo, 2011);

- delimita y fomenta las expectativas profesionales en los estudiantes a partir de roles de género culturalmente asignados (Rico y Trucco, 2014 citado en Céspedes y Robles, 2016);

- presenta una negación e invisibilización de contenidos y formas de relacionarse que están fuera de lo heteronormativo (Fundación Todo Mejora Chile, 2016).

A partir de los antecedentes expuestos, para el presente estudio se plantea la propuesta de Ximena Azúa y Alejandra Farías (2017): "Modelo teórico que identifica el sexismo y la discriminación de género en interacciones pedagógicas" como la herramienta para identificar sesgos de género en el aula. Así, mientras la taxonomía de Krathwohl (Bloom, 1974) incluye objetivos que describen proposiciones de resultados de aprendizajes en las manifestaciones conductuales de los estudiantes que consideran intereses, emociones, actitudes, valores, juicios y formas de adaptación personal y social, el modelo de Azúa y Farías (2017) propone una lógica clasificatoria para las prácticas pedagógicas realizadas predominantemente por el profesorado hacia los estudiantes. Esta propuesta imita la figura de la pirámide, donde desde la base hacia la parte superior se posicionan cinco categorías: invisibilizar, rechazar, naturalizar, modificar y transformar.

"Invisibilizar" se entiende como vetar, marginar y/u ocultar las expresiones o formas de conocimiento que no cumplan con cánones 
hegemónicos de masculinidad y femineidad, es decir, el hecho de ni siquiera percibir la presencia de diferencias que se traducen en discriminación y violencia, ya sea física, sicológica o simbólica. Por otra parte, "rechazar" sucede cuando, si bien se identifican diferencias en el trato hacia hombres y mujeres o identidades no binarias, estas conllevan denigraciones y/o ataques. En el centro de la pirámide se ubica "naturalizar", concepto que se comprende como aquellas acciones que contribuyen a la reproducción de los estereotipos hegemónicos de masculinidad y femineidad, normalizando la esencialización ${ }^{7}$. Una categoría más arriba de la pirámide se encuentra "modificar", que significa dar cuenta de estas diferencias que se traducen en igualdad y, en función de estas, desarrollar instancias acotadas de reflexión y/o crítica hacia estos cánones hegemónicos de masculinidad y femineidad. Por último, en la cima de la pirámide se ubica "transformar", que se entiende como un quiebre del orden hegemónico establecido respecto de cánones y estereotipos de género, y las desigualdades que conllevan, desarrollando e incentivando acciones y contenidos que contribuyan a cuestionar y transformar dicha hegemonía.

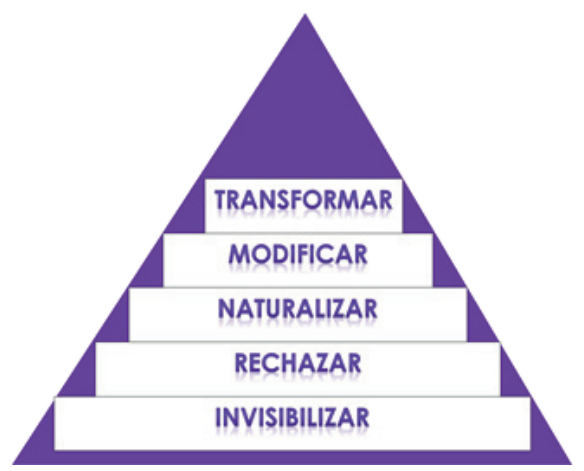

Figura 1. Modelo teórico que identifica el sexismo y la Discriminación de género en interacciones pedagógicas por Azúa y Farías (2017).

Se comprende "esencialización" como el atribuido a características y roles a mujeres y hombres como algo inherente a su género, imponiendo ciertas formas de hacer y ser (Lagarde, 2005; Lamas, 1996). 


\subsection{Educación parvularia en Chile}

Chile ha realizado progresos evidentes en los últimos años en diversos aspectos de la educación parvularia. Hoy cuenta con una institucionalidad mucho más definida y robusta, donde destaca la creación de la Subsecretaría de Educación Parvularia (2015) y la Intendencia de Educación Parvularia dentro de la Superintendencia de Educación. También se encuentra en proceso la organización de una unidad especializada dentro de la Agencia de Calidad, lo que significa un claro fortalecimiento institucional en el plano del aseguramiento de la calidad (Mineduc, 2016; Mineduc s/f). En la misma dirección se ha avanzado en mejorar las condiciones laborales de estas profesionales, así como también los estándares de su formación inicial docente.

En Chile, la educación parvularia es una profesión altamente feminizada ${ }^{8}$, que se ocupa de la formación de niños desde los 3 meses hasta los 5 años; a partir de los 6 años ingresan al ciclo de educación básica. Diversos estudios han catalogado la educación parvularia como crucial, pues la primera infancia corresponde a un período de gran desarrollo humano, señalando que es durante esta etapa que el cerebro — debido a una sobreproducción sináptica — se desarrolla a un ritmo más rápido (Arzola y Camhi, 2013; Shonkoff \& Phillips, 2000), así como también "la capacidad para generar las bases del desarrollo social, emocional y mental es más alta que en cualquier otro tramo etario; es más: decae con el tiempo, presentando en este nivel un aprendizaje más efectivo" (Sánchez, 2017).

A pesar de lo anterior, la formación inicial docente con perspectiva de género en educadores de párvulo es escasa o nula. En un estudio realizado por Valentina Ulloa (2017) se revisaron los planes curriculares de 10 instituciones de educación superior

8 Según el Informe de caracterización de la educación parvularia, durante el año 2018 de un total 27.026 educadores de párvulo, 27 correspondían a varones (Subsecretaría de Educación Parvularia, 2019). 
con los mejores resultados en la Prueba Inicia ${ }^{9}$, donde se identificó que "ninguno posee ramos enfocados en formar a educadores y educadoras respecto de educación en sexualidad, afectividad y/o género, al menos como parte estructural de sus planes de estudios" (pp. 14-15).

La educación parvularia — ya sea en escuela o en jardín infantil— también es relevante en la formación de los niños, pues es durante la primera infancia donde ocurre la socialización primaria, la que se comprende como la más importante para internalizar significaciones del mundo social en donde están inmersos, a fin de convertirlos en miembros de la sociedad (Berger y Luckmann, 1968; Bourdieu, 2000). Además, las experiencias durante estos primeros años de vida son determinantes en la percepción que tienen los niños de sí mismos, las relaciones con los demás y la capacidad de confiar en otros (Siegel, 1999).

Un ejemplo de lo anterior es el estudio realizado por Del Río y Strasser (2013) a 81 niños y niñas de kínder de escuelas de Santiago centro, a quienes se les aplicó un instrumento para evaluar las creencias implícitas que poseían acerca de las diferencias de género en la capacidad académica. Los resultados apoyaron la hipótesis de que a la edad de 5 años los niños ya tienen expectativas estereotipadas respecto del logro académico que debieran alcanzar.

La socialización de género en la cual están inmersos los niños durante su educación parvularia depende de diversos factores, donde la práctica docente es fundamental. A partir de esto es que se instala la necesidad urgente de pensar en la inclusión de la perspectiva de género en la formación de docentes de párvulos y en programas de educación continua, aspecto que ya han indicado expertos (Falabella y Opazo, 2014) y que incorporan las nuevas bases de educación parvularia (Mineduc, 2018).

9 La prueba Inicia fue creada el año 2008 y consiste en una evaluación voluntaria dirigida a docentes de educación parvularia y básica que involucra conocimientos disciplinarios y pedagógicos básicos considerados necesarios para ejercer la profesión docente. Su objetivo es el de fomentar procesos de reflexión y transformación de las instituciones que imparten carreras de formación inicial docente (San Martín, Rivero, Bascopé y Hurtado, 2015). 
En relación con esta temática, estudios nacionales han dado cuenta de las diferencias de género que suceden en el aula en el contexto de la educación parvularia. Uno de ellos es el de Grau (2018), donde se identificaron diferencias de género en torno a las percepciones del juego y a las prácticas lúdicas desarrolladas. A partir de esto, se observó que si bien niños y niñas relevan la importancia de contar con espacios amplios, infraestructura adecuada, acceso a la naturaleza y a materiales o recursos variados para el juego, existen diferencias en el tipo de juego que mencionan unos y otras: mientras los varones mencionan muy frecuentemente el fútbol u otros juegos físicos con reglas, comparativamente las niñas mencionan más los juegos sociodramáticos o de roles, como "jugar al doctor" o "a la familia".

Por otra parte, en el mismo estudio se observó que son los varones quienes tienden a dar cuenta explícitamente de un juego generizado: juegos que son "para niñas" y otros "para niños". Así, por ejemplo, algunos arguyen que a las niñas "no les gusta" jugar al fútbol, o bien que "no saben cómo jugarlo", lo que es rebatido por algunas niñas, quienes indican que en realidad "los niños no nos dejan" practicar este juego. En efecto, en el estudio se identifica una relativa "invasión" de los espacios exteriores por parte del fútbol masculino, relegando a un segundo plano las oportunidades y espacios para las niñas durante los momentos de recreación (Grau, 2018).

Otro estudio relacionado con la misma temática corresponde al realizado por Cortázar y Vielma (2017), el que tuvo como objetivo estimar el efecto de la educación parvularia pública chilena en los resultados académicos de los niños en el Sistema de Medición de la Calidad de la Educación (Simce) de cuarto año básico, e identificar si estos varían en función del género de los niños, y del número de años de participación en la educación parvularia. Los resultados obtenidos dan luz respecto de los efectos de la educación parvularia en los resultados académicos de manera diferenciada por género, donde "los niños se benefician más que las niñas al asistir a la educación parvularia pública en Chile" (p. 34) lo cual, según lo señalado por el mismo estudio, puede deberse a la diferencia de expectativas que la cultura fomenta para niños y niñas — donde las de los primeros son 
más altas—o, por otro lado, podría deberse a que los niños "tienen más espacio para aprender en estos programas. De esta manera, las niñas tendrían un techo más bajo de aprendizaje en los programas de educación parvularia en Chile" (pp. 37-38).

A partir de esto surge la interrogante relacionada con la práctica docente, ya que los resultados académicos antes descritos estarían siendo motivados por el ejercicio pedagógico en el nivel de educación de párvulos. Los niños, de acuerdo con estos modelos, se enfrentan a una socialización primaria altamente sesgada que modifica su trayectoria educacional, reproduciendo estereotipos de género y mermando, muchas veces, las posibilidades de desarrollo académico y social equitativo.

\section{Metodología}

La presente investigación se realizó en el marco de un estudio elaborado por un equipo de la Facultad de Ciencias Sociales de la Universidad de Chile. El objetivo del estudio fue rediseñar y ajustar la pauta del Mineduc para la identificación de sesgos de género en la práctica docente, con el propósito de que esta contemplara dimensiones e indicadores cualitativos que fuesen factibles de ser utilizados en condiciones de corrección de portafolios del proceso regular de la evaluación docente. De manera similar, también se abordaron los objetivos de rediseñar, ajustar y aplicar la pauta para la caracterización de sesgos de género en la práctica docente, de modo que incluyera además dimensiones e indicadores cualitativos, a fin de generar perfiles de los docentes.

En una primera etapa del estudio, el equipo se propuso rediseñar las pautas de identificación y caracterización de sesgo de género para el Módulo 2 de la evaluación docente ${ }^{10}$, que consideraba:

a. la observación — por parte del equipo central — de una muestra de videos marcados con sesgo de género (30 videos) del Módulo

10 El Módulo 2 de dicha evaluación consiste en la muestra de la práctica del docente a través de la grabación de una clase de aproximadamente 40 minutos. 
60 EL DESAFÍO DE UNA EDUCACIÓN NO SEXISTA EN LA FORMACIÓN INICIAL: PRÁCTICAS DOCENTES DE EDUCADORAS DE PÁRVULO EN ESCUELAS PÚBLICAS CHILENAS - X. Azúa, D. Lillo, P. Saavedra

2 de la evaluación docente 2016, con el fin de realizar un análisis de aplicabilidad y contenidos (dimensiones e indicadores) que abordaba la pauta original;

b. una revisión detallada tanto de la literatura actualizada en torno a la problemática como al acercamiento a experiencias nacionales e internacionales, desde las que surgen los criterios a considerar en la pauta, a saber:

- Criterio 1: Uso del lenguaje. Este criterio se refiere al uso del lenguaje por medio de instrucciones y denominaciones estereotípicas que promueven o dificultan una educación no sexista.

- Criterio 2: Diseño pedagógico. Considera un diseño, el uso de los contenidos y la forma de evaluar que promueve o dificulta una educación no sexista.

- Criterio 3: Corporalidad e interacciones que promuevan una educación no sexista. Se refiere a las acciones que promueve el docente en favor de reconocer las diversas formas de relacionarse, basándose en una educación que promueve la formación no sexista.

c. Proceso de validación con tres jueces expertos, el cual tuvo por objetivos:

- Valorar la pertinencia de los criterios en la observación de un desempeño que promueva/niega una práctica no sexista.

- Valorar la coherencia interna de los criterios, dimensiones y descriptores.

- Valorar la claridad en la formulación de cada criterio, dimensiones y descriptores.

- Seleccionar una dimensión por cada criterio.

Así, se abordó directamente el objetivo de rediseñar y ajustar las pautas del Mineduc para la identificación y caracterización de sesgos de género en la práctica docente, con el propósito de que estas contemplaran dimensiones e indicadores cualitativos que fueran factibles de ser utilizados en condiciones de corrección del proceso de evaluación docente. 
Una segunda etapa correspondió al pilotaje de las pautas con una submuestra proporcional al universo docente —entregada por el Mineduc_-de 146 videos de clases en establecimientos educacionales dependientes del Estado, correspondientes al Módulo 2 de la evaluación docente, los cuales fueron observados por un total de 16 correctores. El pilotaje fue aplicado a videos correspondientes a educación parvularia, nivel básico 1 (NB1) y nivel básico 2 (NB2), educación media, educación diferencial y educación de adultos. Para establecer la fiabilidad de las rúbricas, se propuso una doble revisión del 20\% de los videos, es decir, 28 de los videos fueron revisados dos veces con el propósito de evaluar las rúbricas y calcular la fiabilidad por correlación test-retest. A continuación, se calculó el coeficiente Kappa de Cohen para cada uno de los indicadores, ya que este proporciona una medida del grado de acuerdo entre dos jueces al evaluar cierto fenómeno u objeto (Cohen, 1960).

Una tercera etapa del estudio correspondió a la aplicación de la Pauta de caracterización solamente con el fin de generar perfiles de los docentes; en esta etapa 16 correctores revisaron 596 videos correspondientes al Módulo 2 de la evaluación docente. Para el tratamiento de la información se realizó un análisis descriptivo de los resultados obtenidos; cabe destacar que debido a la naturaleza de las variables en análisis (tanto el nivel educativo como las categorías de respuestas de cada indicador corresponden a variables categóricas), se decidió informar los resultados generando tablas de frecuencia por sobre el cálculo de estadísticos, como la media o la desviación estándar. Estos últimos necesitan que los fenómenos en estudio se encuentren —al menos- en un nivel intervalar de medición, lo que no es posible de asumir en este caso, ya que no se trabaja con puntajes, sino con categorías de respuesta. Finalmente, y con el objetivo de dar cuenta de las preguntas de investigación de tipo relacional, se realizó un análisis multivariable, específicamente, el análisis de correspondencias múltiples, con el fin de generar mapas perceptuales que representaran gráficamente las relaciones que se encontraban entre variables para facilitar la creación de perfiles.

Para este artículo, se utilizan los resultados obtenidos en la etapa tres de este estudio (total de 596 videos), en particular interesa 
exponer lo que ocurre en el nivel de educación parvularia $(n=70)$, que en su totalidad se desempeñan en nivel medio y transición en establecimientos educacionales dependientes del Estado. La muestra fue aleatoria a nivel nacional, con una representatividad del universo docente, correspondiente a diversas regiones del país, zonas rurales y urbanas $^{11}$. De esta manera, la muestra quedó representada de la siguiente forma:

Tablal

Edad por tramo

\begin{tabular}{lcc}
\hline & $N$ & $\%$ \\
\hline Menores de 30 años & 6 & 8,6 \\
\hline $31-39$ años & 13 & 18,6 \\
\hline $40-50$ años & 25 & 35,7 \\
\hline Sobre 51 años & 26 & 37,1 \\
\hline Total & 70 & 100,0 \\
\hline
\end{tabular}

Fuente: Elaboración propia.

Tabla 2

Trayectoria docente

\begin{tabular}{lcc}
\hline & $N$ & $\%$ \\
\hline Tramo inicial & 12 & 17,1 \\
Tramo temprano & 36 & 51,4 \\
Tramo avanzado & 22 & 31,4 \\
\hline Total & 70 & 100,0 \\
\hline
\end{tabular}

Fuente: Elaboración propia.

Adicionalmente a dicha información, tras la revisión de los videos los correctores informaron que la muestra contemplaba solo docentes mujeres, lo que se comprende por la excesiva feminización profesional en la educación parvularia.

11 Cabe señalar que la corrección de la evaluación docente es anónima, es decir, la única información que se tiene de cada docente es su número de identificación y zona del país donde se ubica el establecimiento en el que se desempeña. Adicionalmente para el presente estudio la unidad del Mineduc responsable del proceso entregó información respectiva del rango etario y la trayectoria docente. 


\section{Resultados}

A continuación, se presentan los análisis descriptivos a partir de los resultados obtenidos luego de la aplicación de la Pauta de caracterización en 596 videos (etapa tres del estudio), focalizándose en la observación del nivel de educación de párvulos. Se presenta el análisis de subdimensiones e índices de los criterios planteados para el nivel educación parvularia $(n=70)$ en establecimientos educacionales escolarizados, con una muestra nacional que toma en cuenta sectores rurales y urbanos, y contempla solo docentes mujeres. Posteriormente se presenta el análisis multivariable de componentes múltiples, con el fin de dar a conocer la relación entre las distintas variables para ejemplificar cómo se conformaron ciertos grupos con características similares entre las educadoras.

La Pauta de caracterización (Anexo 1) está compuesta por tres criterios (Uso de lenguaje, Diseño pedagógico e Interacción docente) y, a su vez, cada criterio está constituido por dos subdimensiones, con un total de 18 variables de observación que responden a acciones que modifican/transforman, naturalizan y rechazan/invisibilizan. Las categorías se puntuaron de la siguiente manera:

- Siempre/La mayor parte de las veces (4)

- Frecuentemente (3)

- Ocasionalmente (2)

- Nunca/Rara vez (1)

- No aplica (0)

Así, las subdimensiones corresponden a la suma de los valores obtenidos en las distintas preguntas de la Pauta de caracterización. En el caso de las preguntas $\mathrm{P} 1, \mathrm{P} 4, \mathrm{P} 7, \mathrm{P} 10, \mathrm{P} 13$ y P16, correspondientes al tramo "modificar/transformar" de la pauta, se recodificaron los valores para que coincidieran con el sentido de las otras preguntas de la subdimensión, en tanto dichas preguntas implicaban que, por ejemplo, si se respondía Siempre/La mayor parte de las veces esto correspondería a la conducta sin sesgo; mientras que si se respondía la misma categoría en las otras dos preguntas de la subdimensión, correspondería a sesgo. De esta manera, al recodificar los valores de 
64 EL DESAFÍO DE UNA EDUCACIÓN NO SEXISTA EN LA FORMACIÓN INICIAL: PRÁCTICAS DOCENTES DE EDUCADORAS DE PÁRVULO EN ESCUELAS PÚBLICAS CHILENAS - X. Azúa, D. Lillo, P. Saavedra

las variables, se hace posible la suma de ellas en la subdimensión sin que se altere el resultado.

A continuación, se presentan los principales resultados obtenidos en el análisis descriptivo de la aplicación de la Pauta de caracterización en el nivel educación parvularia.

\subsection{Total de criterios por trayectoria y edad}

Se presentan los resultados descriptivos del nivel educación parvularia, indagando en la puntuación de los índices por criterio de acuerdo con el tramo en su trayectoria docente y tramos de edad. Las observaciones "no aplica" fueron tratadas como datos perdidos.

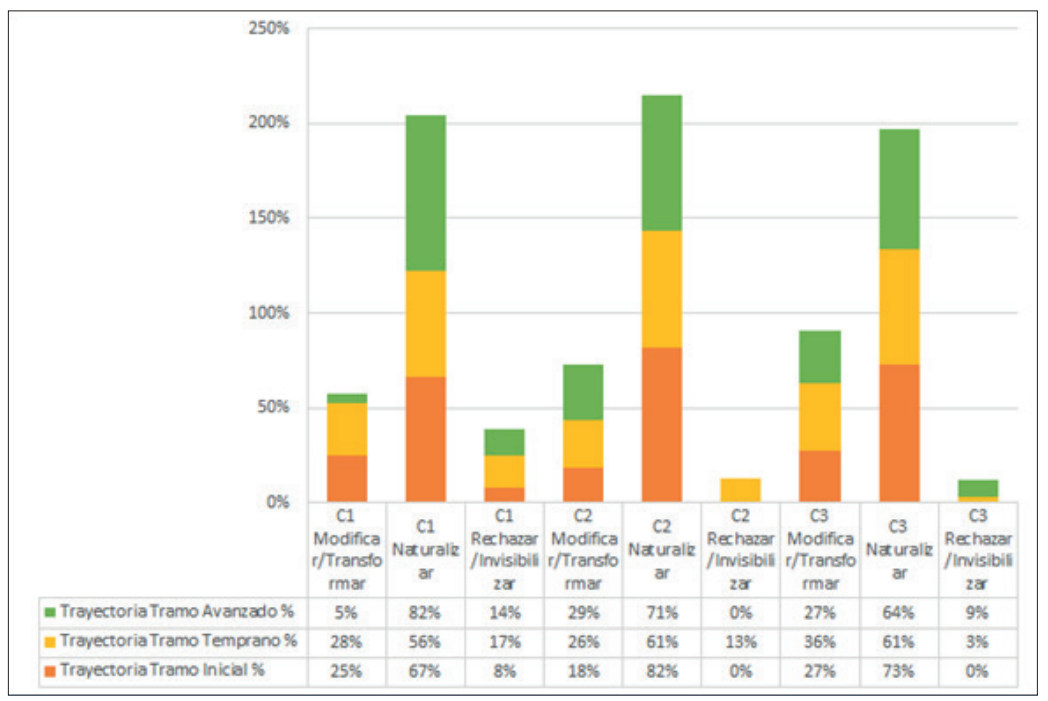

Figura 2. Criterios v/s trayectoria.

Fuente: Elaboración propia.

De acuerdo con la Figura 2, es posible constatar que en los tres tramos de trayectoria y en los tres criterios, la gran mayoría de los casos observados corresponde a la categoría "naturalizar". Llama la atención que en el tramo inicial existen casos en los que no se observa "rechazar/invisibilizar" en los criterios de Diseño pedagógico y Corporalidad e interacciones que promuevan una educación no sexista; en el tramo avanzado tampoco se observa "rechazar/ 
invisibilizar" en el criterio de Diseño pedagógico. Por el contrario, hay que destacar que el tramo temprano es el que tiene un mayor número $(n=36)$; también presenta los mayores porcentajes en comparación con los otros tramos en el nivel "rechazar/invisibilizar", y el mayor porcentaje en "modificar/transformar", obteniendo un 36,1\% en el criterio Corporalidad e interacciones que promuevan una educación no sexista.

Como es la tendencia en los distintos niveles, en educación parvularia si bien se aprecian esfuerzos por generar acciones más inclusivas y equitativas, se mantiene la naturalización como preponderante. Los tres tramos de trayectoria no presentan diferencias sustantivas, pero sería interesante incorporar logros en el área de inclusión de enfoque de género como meta para ascender en dichos tramos. A raíz de estos resultados, el equipo decidió indagar en el comportamiento de los puntajes del índice por tramos etarios, con el fin de comparar las trayectorias y las edades.

Tabla 3

Criterios v/s edad

\begin{tabular}{|c|c|c|c|c|c|c|c|c|c|}
\hline & & \multicolumn{8}{|c|}{ Edad por tramo } \\
\hline & & \multicolumn{2}{|c|}{$\begin{array}{c}\text { Menores } \\
\text { de } 30\end{array}$} & \multicolumn{2}{|c|}{$31-39$} & \multicolumn{2}{|c|}{$40-50$} & \multicolumn{2}{|c|}{ Sobre 51} \\
\hline & & $n$ & $\%$ & $N$ & $\%$ & $n$ & $\%$ & $\mathrm{~N}$ & $\%$ \\
\hline \multirow[t]{3}{*}{$\begin{array}{l}\text { Criterio 1: Uso } \\
\text { del lenguaje }\end{array}$} & $\begin{array}{l}\text { Modificar/ } \\
\text { transformar }\end{array}$ & 1 & $16,7 \%$ & 2 & $15,4 \%$ & 8 & $32,0 \%$ & 3 & $11,5 \%$ \\
\hline & Naturalizar & 5 & $83,3 \%$ & 8 & $61,5 \%$ & 15 & $60,0 \%$ & 18 & $69,2 \%$ \\
\hline & $\begin{array}{l}\text { Rechazar/ } \\
\text { invisibilizar }\end{array}$ & 0 & $0,0 \%$ & 3 & $23,1 \%$ & 2 & $8,0 \%$ & 5 & $19,2 \%$ \\
\hline \multirow[t]{3}{*}{$\begin{array}{l}\text { Criterio 2: Diseñ } \\
\text { pedagógico }\end{array}$} & $\begin{array}{l}\text { oModificar/ } \\
\text { transformar }\end{array}$ & 2 & $40,0 \%$ & 0 & $0,0 \%$ & 7 & $31,8 \%$ & 7 & $28,0 \%$ \\
\hline & Naturalizar & 3 & $60,0 \%$ & 9 & $81,8 \%$ & 14 & $63,6 \%$ & 17 & $68,0 \%$ \\
\hline & $\begin{array}{l}\text { Rechazar/ } \\
\text { invisibilizar }\end{array}$ & 0 & $0,0 \%$ & 2 & $18,2 \%$ & 1 & $4,5 \%$ & 1 & $4,0 \%$ \\
\hline \multirow{3}{*}{$\begin{array}{l}\text { Criterio 3: } \\
\text { Corporalidad e } \\
\text { interacciones } \\
\text { que promuevan } \\
\text { una educación } \\
\text { no sexista }\end{array}$} & $\begin{array}{l}\text { Modificar/ } \\
\text { transformar }\end{array}$ & 1 & $16,7 \%$ & 4 & $33,3 \%$ & 10 & $40,0 \%$ & 7 & $26,9 \%$ \\
\hline & Naturalizar & 5 & $83,3 \%$ & 8 & $66,7 \%$ & 14 & $56,0 \%$ & 17 & $65,4 \%$ \\
\hline & $\begin{array}{l}\text { Rechazar/ } \\
\text { invisibilizar }\end{array}$ & 0 & $0,0 \%$ & 0 & $0,0 \%$ & 1 & $4,0 \%$ & 2 & $7,7 \%$ \\
\hline
\end{tabular}

Fuente: Elaboración propia. 
Como se observa en la Tabla 3, se mantiene la tendencia observada en los tramos de trayectoria, obteniendo el mayor número de observaciones de los criterios en la categoría "naturalizar" en todos los tramos etarios. A modo general, llama la atención la baja cantidad de educadoras de párvulo menores de 30 años $(n=6)$ y entre 31 y 39 años $(n=13)$, de ahí que los puntajes de estos grupos parecen extremos en comparación con los demás tramos.

En el criterio Uso del lenguaje, si bien la tendencia es la categoría "naturalizar", es destacable que el tramo etario 40-50 años obtiene un porcentaje alto en "modificar/transformar" (32\%) y, por el contrario, el tramo 31-39 obtiene un porcentaje de 23,1\% en "rechazar/invisibilizar". Con ello se pone en duda la concepción de que a mayor edad se establecerían relaciones menos equitativas, ya que en el criterio Uso de lenguaje (indicaciones y cómo se nombra a los estudiantes) serían las educadoras entre 40 y 50 años quienes tienden a presentar acciones con menos sesgos.

En cuanto al criterio Diseño pedagógico, que comprende el uso de material pedagógico y ejemplos en clase, el tramo 31-39 años presenta $0 \%$ en la categoría "modificar/transformar" y 18,2\% en "rechazar/invisibilizar", superando a los otros niveles en cuanto a porcentaje, pues le siguen los tramos 40-50 (4,5\%) y sobre 50 (4\%). Las más jóvenes no presentan observaciones en "rechazar/ invisibilizar". Por otro lado, la categoría "modificar/transformar" presenta porcentajes más altos que en el criterio Uso del lenguaje, siendo las más jóvenes quienes presentan un $40 \%$ de las observaciones en el tramo etario, seguidas por el grupo de $40-50$ años con 31,8\% de las observaciones.

Finalmente, el criterio Corporalidad e interacciones que promuevan una educación no sexista, que comprende las interacciones tanto entre docente y estudiantes como entre estudiantes, se mantiene la tendencia de "naturalizar" como la acción más observada. No obstante, cabe destacar que en este criterio se concentran los mayores porcentajes en la categoría "modificar/transformar" y los menores en "rechazar/invisibilizar". El grupo de educadoras entre 40 y 50 años obtiene el mayor porcentaje en comparación con su propio grupo 
etario (40\%), seguido por el grupo entre 31 y 39 años (33,3\%) y sobre 50 años $(26,9 \%)$. Son las educadoras de menor edad quienes obtienen menor porcentaje de observaciones (16,7\%).

En cuanto a las posibles coincidencias entre tramos de trayectoria y edad, se observa que el tramo temprano es donde se obtienen porcentajes que demuestran menor sesgo de género en comparación con los otros tramos, lo que se condice con la edad de las educadoras. Así, son los grupos ubicados en el "medio" de ambas variables (ni muy jóvenes, ni muy mayores, y en el segundo tramo de la trayectoria docente) los que presentan acciones en la línea de la modificación. Si bien las acciones naturalizadas son las que más se observan, existen pequeñas diferencias que se deben potenciar. De este modo, es posible sostener que en el profesorado de educación de párvulos se está focalizando el sesgo en la interacción con los estudiantes a través del uso de lenguaje, en tanto ente normativo, pero se presenta un esfuerzo en el diseño pedagógico para entregar elementos diferentes a la hora de transmitir el contenido de la clase.

\subsubsection{Análisis por subdimensiones}

A continuación se presentan los resultados por subdimensiones con el fin de acotar el análisis e identificar cuáles son los temas que necesitan ser tratados con mayor urgencia. En este caso, se incluyen las observaciones en la categoría "no aplica", la que se refiere a las observaciones que responden a casos en los que no existe la posibilidad — debido a la naturaleza o formato de la clase- de que los desempeños observables puedan ser realizados en el aula.

De acuerdo con el análisis de las subdimensiones, es posible realizar una mirada más fina de lo que está pasando en el aula y dónde se encuentran los mayores índices que expresan sesgo de género. De este modo se destaca que, en la asignación de responsabilidades y la interacción entre docente y estudiantes, se 
encuentran los porcentajes más altos de "modifica/transforma", con $62,9 \%$ de las observaciones en cada subdimensión.

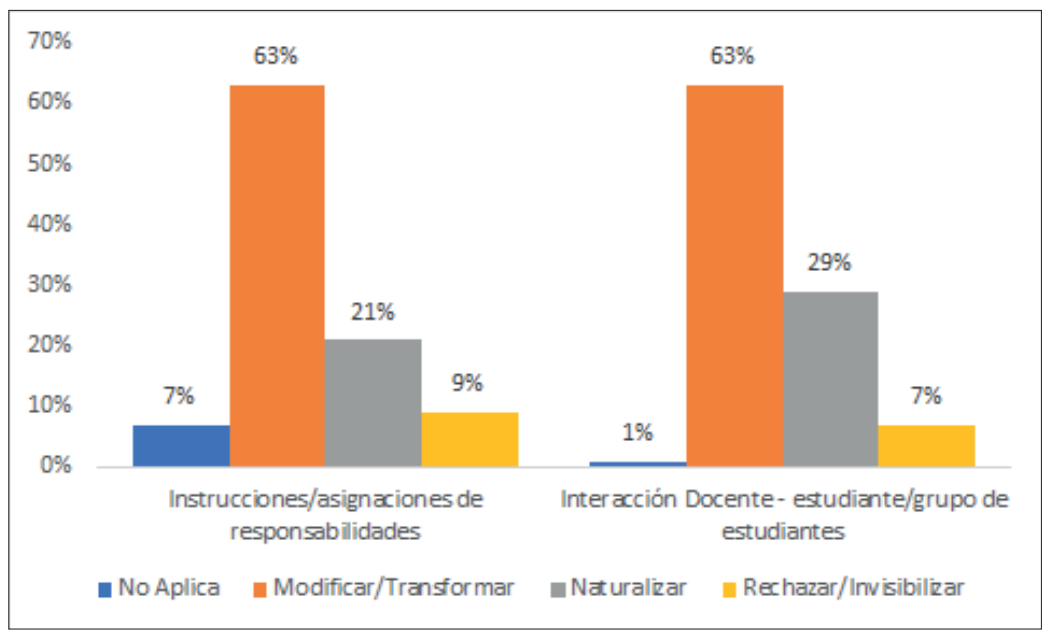

Figura 3. Instrucciones/asignaciones de responsabilidades e Interacción docenteestudiante/grupo de estudiantes.

Fuente: Elaboración propia.

Los resultados indican que se estaría haciendo un esfuerzo por realizar acciones no sesgadas tanto en la interacción con los estudiantes como en el plano del lenguaje a través de la asignación de responsabilidades. Esto contrasta con las observaciones de cómo se nombra al estudiantado, ya que más del $88 \%$ de las mismas corresponde a "naturalizar" $(45,7 \%)$ o a "rechazar/invisibilizar" $(42,9 \%)$.

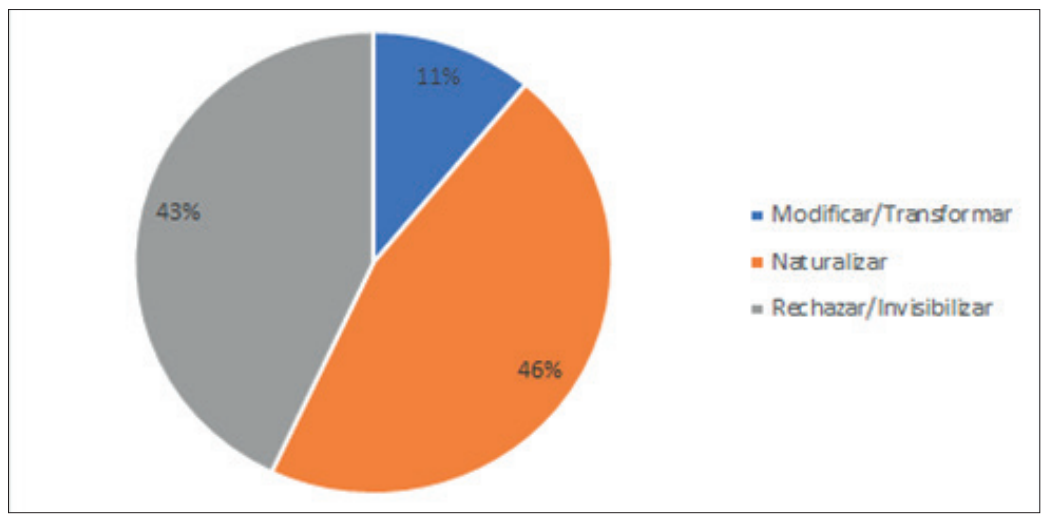

Figura 4. Lenguaje con el que se nombra a sus estudiantes.

Fuente: Elaboración propia. 
Lo anterior indica que se ha naturalizado el uso del genérico masculino como genérico universal, reproduciéndose este fenómeno en el aula según las observaciones realizadas, lo cual indica que las docentes no diferencian por género a sus estudiantes al referirse a ellos, encontrándose en reiteradas ocasiones en cursos mixtos el tratamiento de "alumnos", "niños" al universo del estudiantado, incluso cuando existe solamente un hombre en el curso. Ello es relevante, ya que permite entender cómo la reproducción y la cristalización del androcentrismo permea el uso del lenguaje y se comprende como la formalidad o naturalidad del trato.

Por su parte, en las subdimensiones del criterio Diseño pedagógico existe un avance en cuanto a observaciones en la categoría "modifica/transforma" en el uso de ejemplos de clase (42,9\%), no obstante, en términos del material pedagógico, se tiende a "naturalizar" $(55,7 \%)$, esto se observa en el constante uso del color rosado para las mujeres y del azul para los hombres o cuando se asocian los géneros con ciertas profesiones u oficios.

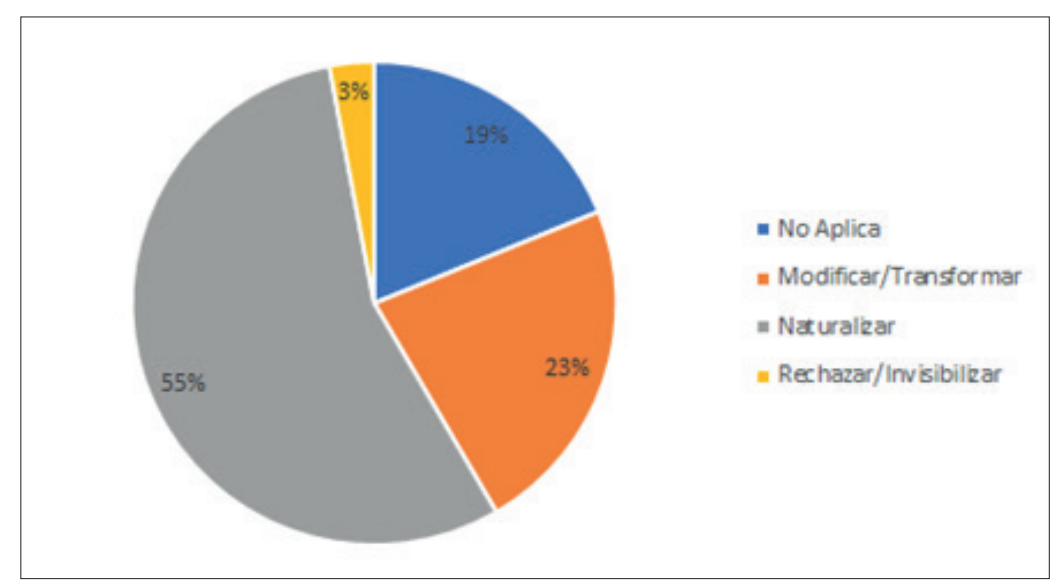

Figura 5. Material pedagógico.

Fuente: Elaboración propia.

En cuanto a la categoría "no aplica", se observa que no se estaría utilizando material docente (18,6\% no aplica en uso de ejemplos y material pedagógico), situación que es preocupante dado que este nivel debería centrar el aprendizaje en torno al uso de dicho material para mejorar la comprensión por parte de los estudiantes y, 
en cambio, se observa que en un porcentaje importante de casos ello no está ocurriendo o, cuando se hace, es reproduciendo estereotipos sexistas.

Por su parte, en el criterio Corporalidad e interacciones que promuevan una educación no sexista se evidencia que, en la interacción docente-estudiantes se presenta un alto porcentaje de acciones observadas como "modificar/transformar" $(62,9 \%)$, lo que indica que existen interacciones libres de sesgo de género que, incluso, instan a modificaciones de conducta en pos de la igualdad de género; por su parte, la interacción entre estudiantes obtiene un $51,4 \%$ de las observaciones en la categoría "naturalizar".

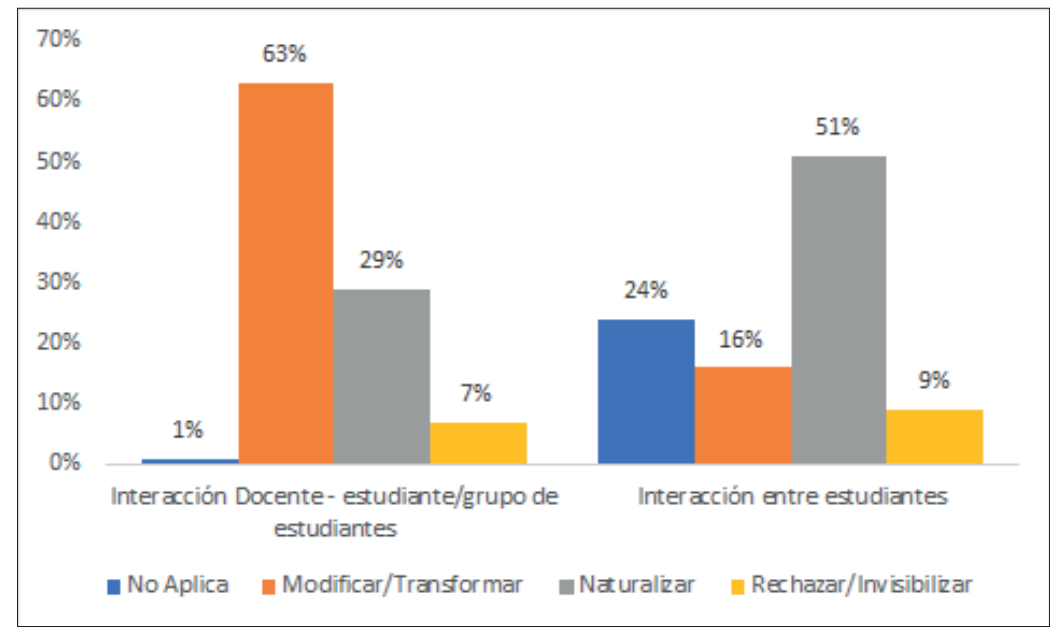

Figura 6. Interacción en el aula.

Fuente: Elaboración propia.

Lo anterior permite observar que si bien existe un esfuerzo por resguardar y cambiar la forma en que cada docente se relaciona con sus estudiantes, no se toma en cuenta o corrige la manera en que ellos interactúan entre sí. Es importante destacar que el instrumento (video grabado de una clase de 45 minutos) no permite observar completamente las interacciones entre los estudiantes, pues el fin del video es captar lo que realiza cada docente, de esta manera se obtiene un $24,3 \%$ de "no aplica". 


\subsubsection{Análisis de correspondencia múltiple}

Más allá de los resultados descriptivos que se pueden obtener a partir de la Pauta de caracterización, interesa también posicionar a los diversos grupos involucrados, de manera de establecer relaciones entre ellos y generar perfiles de acuerdo con sus acciones y la presencia de sesgo de género. En este sentido, y considerando que se analizarán principalmente variables de naturaleza categórica (tanto nominales como ordinales, que corresponden a las respuestas de dicha pauta, además de las variables sociodemográficas autorreportadas por los participantes), se ha optado por seleccionar el Análisis de Correspondencias Múltiples (ACM), el cual considera un total de cinco variables, que se describen a continuación:

- Edad del docente (menores de 30, 31-39, 40-50, sobre 51): variable nominal, peso 1 en el modelo.

- Trayectoria (tramo inicial, tramo temprano, tramo avanzado): variable nominal, peso 1 en el modelo.

- Índice criterio 1 (modificar/transformar, naturalizar, rechazar/ invisibilizar): variable ordinal, peso 1 en el modelo.

- Índice criterio 2 (modificar/transformar, naturalizar, rechazar/ invisibilizar): variable ordinal, peso 1 en el modelo.

- Índice criterio 3 (modificar/transformar, naturalizar, rechazar/ invisibilizar): variable ordinal, peso 1 en el modelo.

El tratamiento de los casos perdidos responde a la exclusión de ellos solamente en los índices, mientras que en las otras variables dichos casos no afectan al modelo. De esta manera, se consideran ocho casos excluidos, utilizando finalmente 62 en el análisis. 
A continuación, la Figura 7 presenta el mapa perceptual obtenido del ACM:

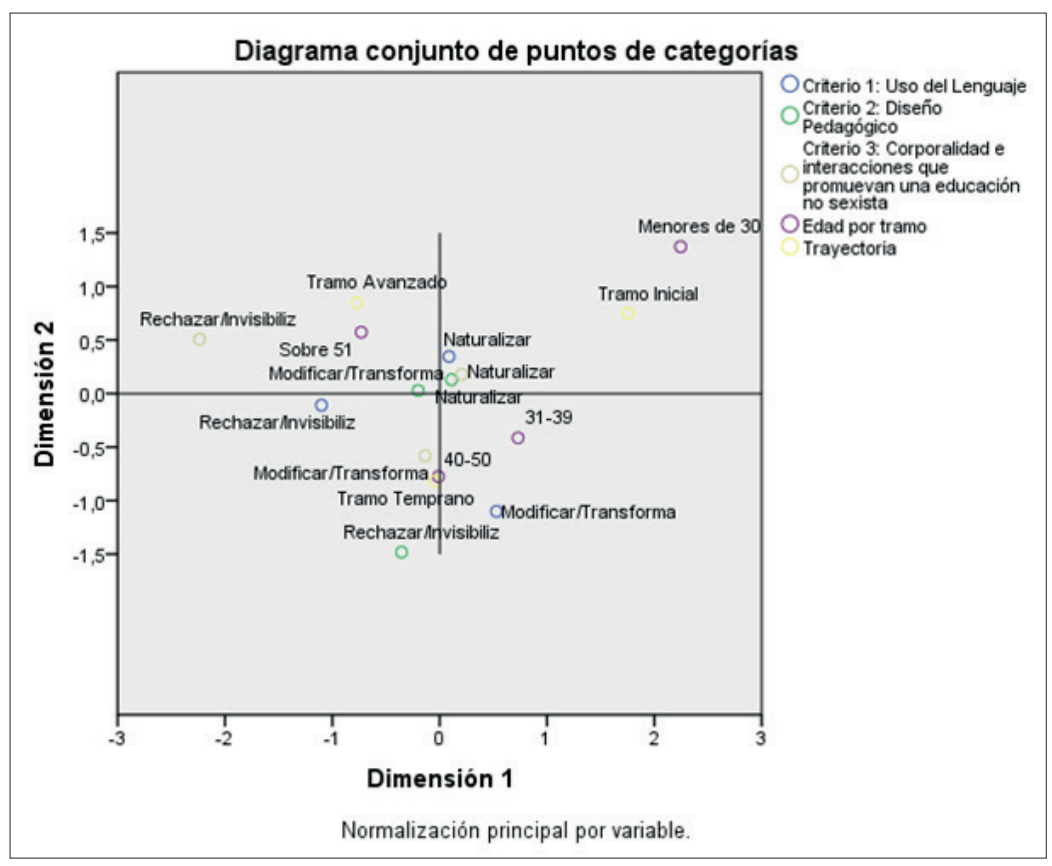

Figura 7. Diagrama conjunto de puntos de categorías (ACM). Fuente: Elaboración propia.

Como se observa en el modelo, si bien no existen grupos claramente diferenciados, es posible establecer algunos que se condicen con el análisis descriptivo. En primer lugar, ubicado en la parte superior izquierda de la figura, se presenta la asociación entre las categorías "rechazar/invisibilizar" del índice del criterio Corporalidad e interacciones que promuevan una educación no sexista, el tramo avanzado en la categoría trayectoria docente, y el tramo etario sobre 51. Sería entonces este grupo el que requiere mayor apoyo en cuanto a interacción docente, con el fin de eliminar acciones sesgadas en el aula.

Por su parte, se identifica un gran grupo en el que las categorías "naturalizar" y "modificar/transformar" no se diferencian de modo significativo, generando un gran grupo de naturalizadoras. En este grupo se encuentra el tramo 31-39 años, el tramo inicial y más 
alejado, las menores de 30 años (que debido a su bajo número $n=5$, implica quedar aislados en el modelo).

El tercer subgrupo corresponde a quienes muestran tendencia a "modificar/transformar" en los criterios Uso del lenguaje y Corporalidad e interacciones que promuevan una educación no sexista, pero que presentan acciones de "rechazar/invisibilizar" en el criterio Diseño pedagógico. Se trata de educadoras en el tramo etario 40-50 años y/o que están en el tramo temprano de la trayectoria docente. En particular llama la atención este grupo, pues ejemplifica los cambios que se están realizando en los modos de actuar de las educadoras, pero que no se condice con cómo se aplica el currículo a sus estudiantes, ya que se mantienen los ejemplos y utilización de material pedagógico con sesgos de género.

Finalmente, se puede destacar que la categoría "rechazar/ invisibilizar" del criterio Uso del lenguaje queda aislada pues, como se observa en el análisis descriptivo, es bastante transversal el uso del lenguaje genérico masculino que presenta sesgos.

\section{Conclusiones}

A partir del estudio realizado y sus resultados, se concluye que las acciones categorizadas como "naturalizar" son las prácticas pedagógicas preponderantes en las educadoras de párvulo del grupo en estudio, de forma transversal en todos los tramos y edades. La naturalización se acentúa en el material de clase estereotipado, la no resolución de conflictos entre estudiantes y, principalmente, en el lenguaje, donde el uso del masculino como universal se perpetúa en lo cotidiano, incluso a veces siendo contradictorio con otras prácticas que se desarrollan paralelamente y que apelan a un "modificar/ transformar". De este modo, la formación inicial de niños responde a una socialización primaria que tiende a naturalizar las desigualdades de género y a reproducirlas como algo natural, contribuyendo al desarrollo de una relación dialéctica entre escuela y sociedad que perpetúa la jerarquía y la violencia de género. 
74 EL DESAFÍO DE UNA EDUCACIÓN NO SEXISTA EN LA FORMACIÓN INICIAL: PRÁCTICAS DOCENTES DE EDUCADORAS DE PÁRVULO EN ESCUELAS PÚBLICAS CHILENAS - X. Azúa, D. Lillo, P. Saavedra

Lo anterior también demuestra que muchas veces las prácticas docentes de las educadoras que incurren en un sesgo de género no son ejecutadas de forma consciente, lo que significa que, si no hay formación profesional para detectar estas prácticas que reproducen el sexismo en el aula, su reproducción o transformación queda a merced del azar y de las voluntades particulares.

Por otro lado, a través del estudio fue posible identificar grupos docentes con características comunes que permiten indagar en el establecimiento de perfiles de las educadoras de párvulo. En primer lugar, se identifica un grupo docente, que en la investigación se denomina como "resistente al cambio", perteneciente al tramo avanzado, que tienen sobre los 51 años y donde preponderan las acciones de rechazo o invisibilización en las interacciones en el aula. En segundo lugar, se detecta un perfil docente de naturalizadoras caracterizado por encontrarse en el tramo inicial y cuyas representantes tienen menos de 39 años. Por último, se presenta un perfil docente de tramo temprano y entre 40 y 50 años, donde destaca la contradicción, debido a que si bien presentan tendencia a "modificar/transformar" en el uso de lenguaje e interacciones en el aula, en el diseño curricular realizan un salto al otro extremo, presentando acciones categorizadas en el "rechazar/invisibilizar". Este último grupo reafirma lo anteriormente señalado, pues las contradicciones presentadas revelan que no existe una noción o idea unitaria en las educadoras de lo que es una práctica sexista o no sexista, sino que sus acciones responden a nociones o intuiciones individuales respecto de cómo se deben realizar ciertas acciones.

A partir de lo anterior, es posible concluir que existe una necesidad urgente de incorporar con mayor énfasis y prioridad la formación docente con enfoque de género en educación parvularia. Las contradicciones entre acciones sesgadas por género en grupos diversos de educadoras responden a una formación inicial docente del profesorado en general, y educación parvularia en particular, donde los estudios de género no ocupan un espacio significativo y a veces, incluso, no son considerados. Asimismo, en la formación continua, a pesar de que existe una oferta de diversos cursos que abordan estas temáticas, seguirlos depende de una voluntad particular del docente 
y no de una política general que proponga y permita una formación en género transversal desde una etapa profesional temprana.

En relación con esto último, un estímulo que podría motivar al profesorado a cursar capacitaciones en estos temas podría ser la incorporación de logros en el área de inclusión de enfoque de género, como meta para obtener mejores resultados tanto en la carrera como en la evaluación docente, para lo cual también se considera que tendría que revisarse el formato de grabación, que actualmente dificulta la observación de interacciones en clase. Sin embargo, se considera que es necesario tener presente que hay una acción contraproducente en evaluar aquello que no se ha enseñado, es decir, es primordial que para implementar criterios de sesgos de género en la evaluación docente es necesario implementar también formación docente en género.

Por otro lado, como proyección de esta investigación sería interesante realizar una comparación de los resultados obtenidos a partir de las pautas aplicadas en establecimientos de jardines infantiles públicos no escolarizados (pertenecientes a la Junta Nacional de Jardines Infantiles, Junji, por ejemplo). De este modo, se podría observar si existen diferencias en los sesgos de género presentes en el uso del lenguaje, diseño pedagógico e interacciones en aula y así evidenciar si el sistema de escolarización representa o no un factor influyente en la reproducción de prácticas sexista en el aula.

Para finalizar, se hace hincapié en el hecho de que los sesgos de género detectados en el aula, y el impacto que estos tienen en la vida de los niños a partir de su socialización primaria, dan luces de la urgencia de una política nacional que dé cuenta de la importancia de los estudios de género en la formación docente, comprendiendo que no basta con la oferta de cursos en la educación continua, sino que es necesaria una formación inicial docente en estos temas, que permita y apoye el egreso de profesionales que respondan a la exigencia nacional de una educación no sexista. 
76 EL DESAFÍO DE UNA EDUCACIÓN NO SEXISTA EN LA FORMACIÓN INICIAL: PRÁCTICAS DOCENTES DE EDUCADORAS DE PÁRVULO EN ESCUELAS PÚBLICAS CHILENAS - X. Azúa, D. Lillo, P. Saavedra

\section{Referencias}

Arzola, M. y Camhi, R. (2013). Educación preescolar: evidencia y desafíos para Chile. Serie Informe Social, Libertad y Desarrollo, 138, 1-28. Recuperado de https://lyd.org/other/files_mf/sisol38educacionpreescolarevidenci aydesafiosparachilemparzolayrcamhienero2013.pdf

Azúa, X. y Farías, A. (2017). Modelo teórico que identifica el sexismo y la discriminación de género en interacciones pedagógicas. Certificado de registro $\mathrm{N}^{\circ} 283.074$.

Berger, P. y Luckman, T. (1968). La construcción social de la realidad. Buenos Aires: Amorrortu.

Bloom, B. S. (1974). Taxonomía de los objetivos de la educación. La clasificación de las metas educacionales. Buenos Aires: El Ateneo.

Bourdieu, P. (2000). La dominación masculina. Barcelona: Anagrama.

Camacho, J. (2018). Educación científica no sexista. Aportes desde la investigación en Didáctica de las Ciencias. Nomadías, 25, 101-120. http://doi.org.10.5354/0719-0905.2018.51508

Castillo, J. (2011). Equidad educativa y género en Chile: estado de situación del sistema educativo y relaciones de género en la escuela. Revista Latinoamericana de Educación Inclusiva, 5(1), 33-48. Recuperado de http://www.cl.undp.org/content/chile/es/home/library/poverty/ publicaciones_externas/equidad-educativa-y-genero-en-chile--estadode-situacion-del-sis.htmlo

Céspedes, C. y Robles, C. (2016). Niñas y adolescentes en América Latina y el Caribe. Deudas de igualdad. Santiago de Chile: Comisión Económica para América Latina y el Caribe, Cepal.

Chávez Salas, A. (2006). La construcción de subjetividades en el contexto escolar. Revista Educación, 30(1), 187-200. https://doi.org/10.15517/ revedu.v30il.1803

Cohen, J. (1960). A coefficient of agreement for nominal scales. Educational and Psychological Measurement, 20(1), 37-46. https://doi. org/10.1177/001316446002000104

Corrales Mejías, L., Delgado, M., Herrera, C., Pereira, Z., Sancho, J., y Zamora, M. (2005). Sexismo en educación preescolar: la perspectiva docente. Revista Electrónica Educare, 8, 139-155. https://www.revistas.una.ac.cr/ index.php/EDUCARE/article/view/1273

Cortázar, A. y Vielma, C. (2017). Educación parvularia chilena: efectos por género y años de participación. Revista Calidad en la Educación, 47, 1942. http://dx.doi.org/10.4067/S0718-45652017000200019 
Del Río, M. F. \& Strasser, K. (2013). Preschool children's beliefs about gender differences in academic skills. Sex Roles, 68(3-4), 231-238. https://doi. org/10.1007/s11199-012-0195-6

Docente Más (s/f). Qué es la evaluación docente. Recuperado de https://www. docentemas.cl/pages/quienes-somos/que-es-la-evaluacion-docente.php

Facultad de Ciencias Sociales de la Universidad de Chile, Ministerio de Educación y Programa de las Naciones Unidas para el Desarrollo (2017). SDP N 031/2017 - Informe Final Servicio: Elaboración de tipologías sobre sesgos y estereotipos de género en la práctica docente, y desarrollo de material que oriente la práctica docente al respecto. Ministerio de Educación, Santiago.

Falabella, A. y Opazo, C. (2014). Sistema de aseguramiento de la calidad y procesos de mejora: una mirada desde la gestión educativa. Santiago de Chile: Ministerio de Educación de Chile y Unesco.

Finco, D. (2015). Igualdad de género en las instituciones educativas de la primera infancia brasileña. Revista Latinoamericana de Ciencias Sociales, Niñez y Juventud, 13(1), 85-96. https://doi.org/10.11600/169271 5x.1313250214

Fundación Todo Mejora Chile. (2016). Encuesta nacional de clima escolar en Chile. Recuperado de https://todomejora.org/wp-content/ uploads/2016/08/Encuesta-de-Clima-Escolar-2016-FundacionTODO-MEJORA.pdf

Grau, V. (2018). Rol del juego en la educación parvularia. Creencias y prácticas de educadoras en prekinder (Informe final. Proyecto Fonide FX21615). Santiago de Chile: Fondo de Investigación y Desarrollo en Educación.

Guerrero, E., Provoste, P., y Valdés, A. (2006). La desigualdad olvidada: género y educación en Chile. En Hexagrama Consultoras; Facultad Latinoamericana de Ciencias Sociales, Flacso; Instituto de Estudios Sociales Contemporáneos, IESCO-Universidad Central de Bogotá (Eds.), Equidad de género y reformas educativas. Argentina, Chile, Colombia y Perú (pp. 99-150). Santiago de Chile: Autor.

Lagarde, M. (2005). Cautiverios de las mujeres: madresposas, monjas, putas, presas y locas. México, DF.: Universidad Nacional Autónoma de México.

Lamas, M. (1996). Usos, dificultades y posibilidades de la categoría de género. En M. Lamas (Comp.), El género, la construcción cultural de la diferencia sexual (pp. 327-366). México, DF.: Programa Universitario de Estudios de Género, UEG- Universidad Nacional Autónoma de México, UNAM.

Luke, C. (2000). La infancia y la maternidad y paternidad en la cultura popular infantil y en las revistas de cuidados infantiles. En C. Luke 
78 EL DESAFÍO DE UNA EDUCACIÓN NO SEXISTA EN LA FORMACIÓN INICIAL: PRÁCTICAS DOCENTES DE EDUCADORAS DE PÁRVULO EN ESCUELAS PÚBLICAS CHILENAS - X. Azúa, D. Lillo, P. Saavedra

(Comp.), Feminismos y pedagogías en la vida cotidiana (pp. 160-178). Madrid: Ediciones Morata.

Ministerio de Educación de Chile, Mineduc. (2016). Hoja de ruta. Definiciones de política para una educación parvularia de calidad. Recuperado de https://parvularia.mineduc.cl/wp-content/uploads/sites/34/2017/02/ HOJA-DE-RUTA-PDF-VERSI\%C3\%93N-2017.pdf

Ministerio de Educación de Chile, Mineduc. (2018). Bases curriculares. Educación parvularia. Recuperado de https://parvularia.mineduc. cl/2018/03/06/descarga-las-bases-curriculares-la-educacionparvularia-2018/

Ministerio de Educación de Chile, Mineduc y Centro de Perfeccionamiento, Experimentación e Investigaciones Pedagógicas, CPEIP. (2008). Marco para la buena enseñanza. Recuperado de: https://www.docentemas.cl/ descargas/documentos_descargables/MBE2008.pdf

Ministerio de Educación de Chile, Mineduc. (s/f) Trayectorias, avances y desafíos de la educación parvularia en Chile. Análisis y balance de la política pública 2014-2018. Recuperado de: https://parvularia.mineduc. cl/wp-content/uploads/sites/34/2018/03/Trayectorias-avances-ydesaf\%C3\%ADos.pdf

Pateman, C. (1988). El contrato sexual. México, DF.: Anthropos- UAM.

Portal Docente Más (s/f). Qué es la evaluación docente. Recuperado de https:// www.docentemas.cl/pages/quienes-somos/que-es-la-evaluaciondocente.php

Rosetti, J. (1993). La práctica pedagógica discrimina a las mujeres. Efectos sobre la vida adulta. En C. Barattini (Ed.), Educación y género: una propuesta pedagógica (pp. 37-50). Santiago de Chile: Ediciones La Morada-Ministerio de Educación de Chile.

San Martín, E., Rivero, R., Bascopé, M., y Hurtado, C. (2015). ¿Es la prueba Inicia una medida predictiva de efectividad docente? Resultados preliminares del proyecto Fonide $N^{\circ}$ F721265. Recuperado de: https://centroestudios. mineduc.cl/wp-content/uploads/sites/100/2017/07/Informe-FinalF711265-San-Martin.pdf

Sánchez, E. (2017). Desafíos de la institucionalidad en la educación parvularia en Chile. Análisis a partir de la reforma educacional 2014-2018. Revista Estado, Gobierno y Gestión Pública, 30, 45-68. http://doi. org. 10.5354/0717-8980.2018.49240

Servicio Nacional de la Mujer, Sernam. (2009). Análisis de género en el aula. Documento de Trabajo $N^{o} 117$. Recuperado de https://estudios.sernam. 
cl/documentos/?eMTEONDczNw==-An\%C3\%Allisis_de_Genero_en_ el_Aula._

Shonkoff, J. P. \& Phillips, D. A. (Eds.) (2000). From neurons to neighborhoods: The science of early child development. Washington, DC.: National Academy Press.

Siegel, D. (1999). The developing mind. New York: Guilford Press.

Subirats, M. (1994). Conquistar la igualdad. La coeducación hoy. Revista Iberoamericana de Educación, 6, 49-78. Recuperado de https:// dialnet.unirioja.es/servlet/articulo? codigo $=1019459$ \&orden $=$ 28208\&info=link

Subirats, M. y Brullet, C. (1992). Rosa y azul. La transmisión de los géneros en la escuela mixta. Madrid: Instituto de la Mujer.

Subsecretaría de Educación Parvularia (2019). Informe de caracterización de la educación parvularia. Recuperado de: https://parvularia.mineduc.cl/ wp-content/uploads/sites/34/2019/04/estudio-editado.pdf

Ulloa, V. (2017). Estudio sobre la relevancia que tiene la educación en sexualidad, afectividad y género en la educación parvularia (Tesis de magíster inédita). Universidad de Chile, Santiago de Chile.

Valdés, T. (2013). Género en la escuela, o la porfiada desigualdad. Revista Docencia, 49, 46-61. https://www.yumpu.com/es/document/ $\mathrm{read} / 36464789 /$ genero-en-la-escuela-o-la-porfiada-desigualdadrevista-docencia

Recibido: 17/08/2018

Aceptado:22/05/2019 
80 EL DESAFÍO DE UNA EDUCACIÓN NO SEXISTA EN LA FORMACIÓN INICIAL: PRÁCTICAS DOCENTES DE EDUCADORAS DE PÁRVULO EN ESCUELAS PÚBLICAS CHILENAS - X. Azúa, D. Lillo, P. Saavedra

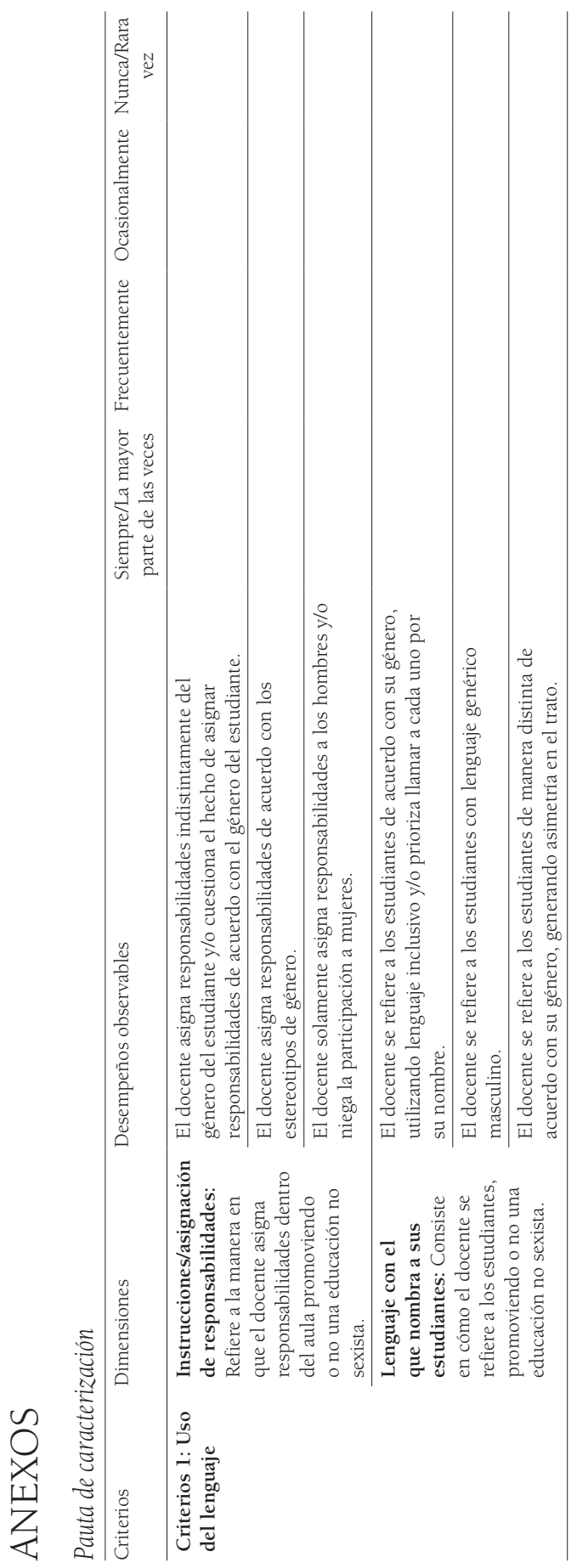




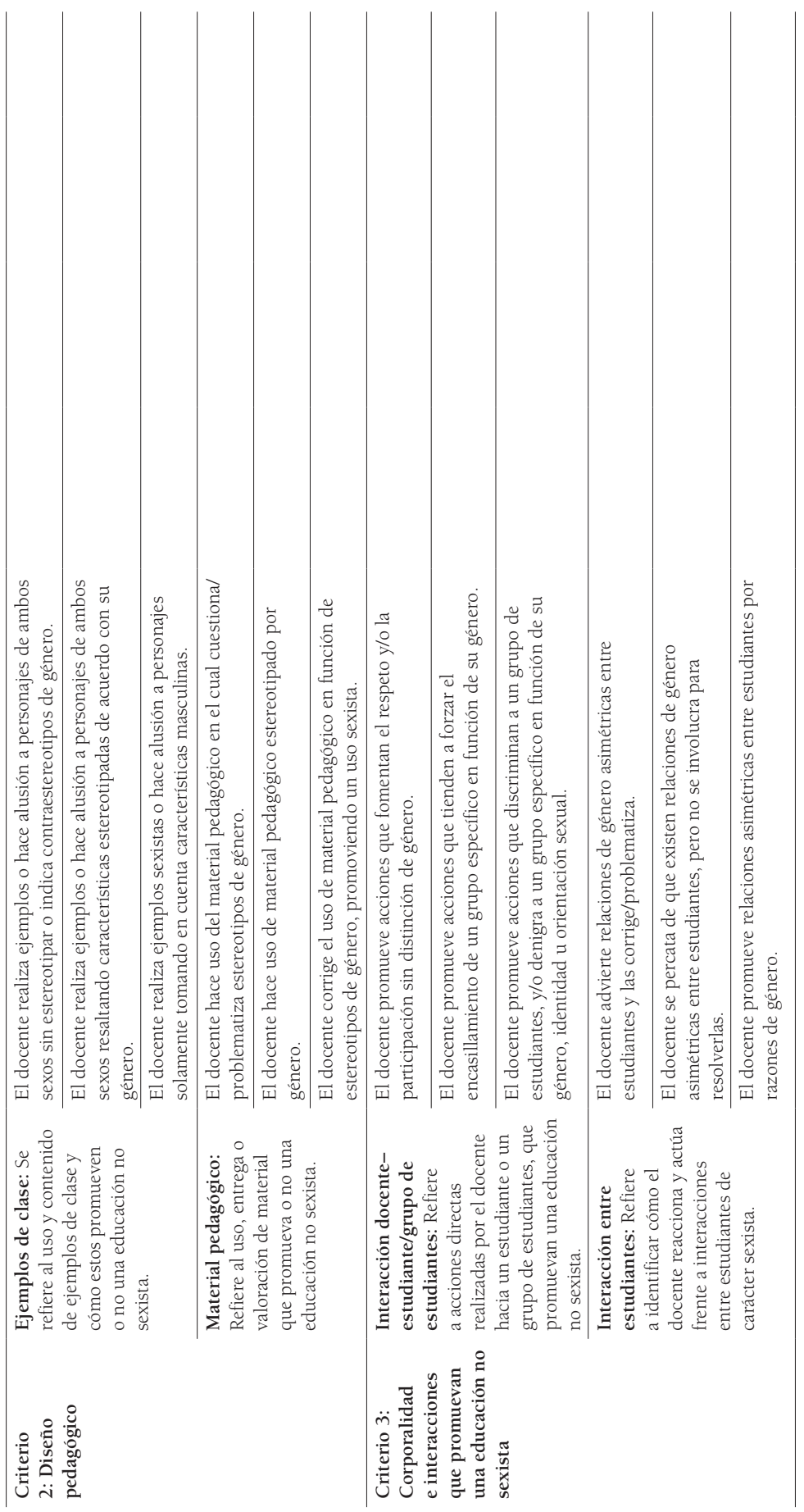


82 EL DESAFÍO DE UNA EDUCACIÓN NO SEXISTA EN LA FORMACIÓN INICIAL: PRÁCTICAS DOCENTES DE EDUCADORAS DE PÁRVULO EN ESCUELAS PÚBLICAS CHILENAS - X. Azúa, D. Lillo, P. Saavedra

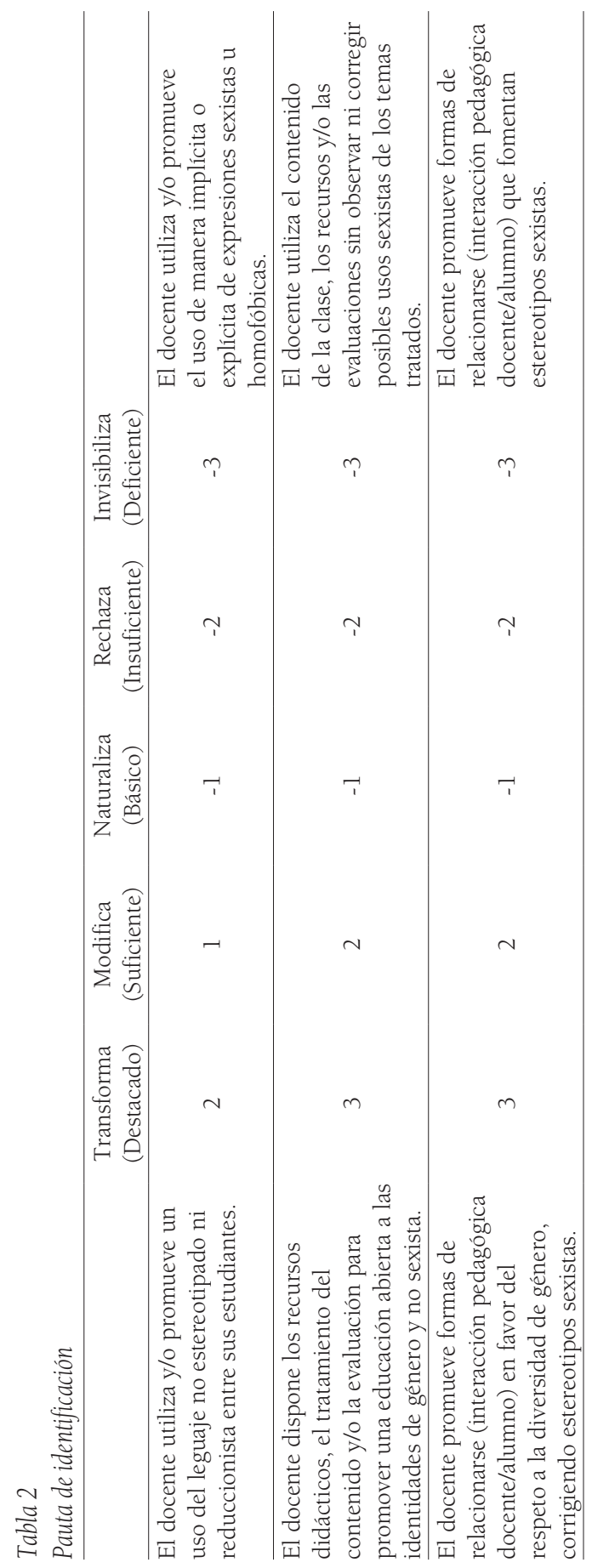

